\title{
Experimental Study on the Influence of
}

\section{Vent Aperture Size and Distribution on Arc Motion and Interruption in Low-Voltage Switching Devices}

\author{
Dongkyu Shin ${ }^{1}$, Igor O. Golosnoy ${ }^{1}$ and Thomas G. Bull ${ }^{2}$ \\ ${ }^{1}$ School of Electronics and Computer Science \\ University of Southampton, Southampton, U.K. \\ 2 TaiCaan Technologies Ltd. \\ 2 Venture Road, Southampton, U.K. \\ ds7g14@soton.ac.uk
}

\begin{abstract}
Enhanced switching performance during the interruption process is achieved when the arc quickly enters and stays within the splitter plate region with the arc itself remaining attached to the surface of the plates. It is well known that the vent design in low-voltage switching devices (LVSDs) has a significant influence on arc motion during an interruption event: however, there has been limited experimental studies correlating arc motion in the whole quenching chamber, including splitter plates region, to the size and distribution of the vent apertures, which are important for plasma flow in LVSDs. This paper uses high speed optical arc imaging to investigate arc motion in a LVSD as the vent aperture conditions are varied. It is shown that the arc moves further and more quickly if there is the larger vent size in the quenching chamber. In addition, the well distributed vent contributes to an increase in arc motion velocity and reduction in total arc duration.
\end{abstract}

Index Terms-Arc imaging system, low-voltage switching devices, switching performance, vent conditions.

\section{INTRODUCTION}

Low-voltage switching devices (LVSDs) are widely utilized in power distribution networks to turn on and off circuits and to protect humans and other connected equipment against overload or short circuit accidents. The quenching chamber is the main volume for switching current in a LVSD and consists of a movable and fixed contact, splitter plates and vents. After contact separation, the arc is established in the quenching chamber and it elongates as the contact gap increases. The arc moves towards the splitter plates by the combination of gas flow and Lorentz forces. When the arc enters the splitter plates, it is divided into several segments and a high arc voltage is generated resulting from multiple arc sheath layers on the surfaces of the splitter plates. The increase in the arc voltage by the splitter plates plays an important role in the interruption process of a LVSD. This achieves the significant reduction in the arc current when compared to the prospective current, which is called the current limitation [1]

\author{
John W. McBride ${ }^{3,4}$ \\ ${ }^{3}$ Faculty of Engineering and the Environment \\ University of Southampton, Southampton, U.K. \\ ${ }^{4}$ University of Southampton Malaysia Campus \\ Nusajaya, 79200, Johor, Malaysia
}

The current limitation is the main feature of low-voltage interruption principle and it has a great influence on switching performance. Normally, enhanced switching performance is achieved by the superior current limitation; when the arc quickly enters and stays within the splitter plate region with the arc itself remaining attached to the surface of the plates.

It is well known that the vent design in LVSDs is a key factor to influence arc motion and current limitation. Therefore, an understanding of detailed arc motion depending on the venting condition is important to design a product and improve switching performance. McBride et al. conducted experimental studies of the influence of the vent size on the arc root time (the time period that the arc root remains in the contact region) by measuring arc motion in a miniature circuit breaker (MCB) through high speed optical imaging system [2]. They found that the arc root time decreases as the vent size increases. Li et al. investigated the simulation of arc motion in the simplified chamber geometry without splitter plates and showed that larger vent size results in increased arc velocity and arc voltage [3]. Wang et al. studied the effect of the geometry of front and back vents on arc motion through 2D magnetohydrodynamic arc modelling [4]. They found that the combination of the central-type front and closed back vent helps enhance the arc velocity. Despite these studies, there has been little empirical work correlating arc motion in the overall quenching chamber (including splitter plates region) to the size and distribution of vent apertures, which are important in determining the arc plasma flow condition during the interruption process.

In this paper, the effect of the vent condition on arc motion is experimentally investigated in an attempt to improve switching performance. LVSD switching tests are carried out by using different kinds of vent. During the switching process, the arc image (brightness) in the quenching chamber is measured by the high speed optic arc imaging system (AIS). The trajectory of the cathode arc root is obtained from the arc images. It is shown that the large and well distributed vent

Identify applicable sponsor/s here. (sponsors) 
contributes to an increase in arc motion velocity and to an improvement of switching performance.

\section{EXPERIMENTAL METHOD}

\section{A. Arc Imaging Measurement}

The arc images (light intensity) inside the quenching chamber are recorded by using the AIS linked to a flexible test apparatus (FTA) [2], [5], [6]. The FTA is designed as the quenching chamber of a MCB and it is used to record arc motion under controlled test conditions. Fig. 1 shows the internal configuration of the FTA. An array of total 109 optical fibres is fitted into the holes of the fibre array block to allow observation of the overall quenching chamber of the FTA (see Fig. 2). There are 32 fibres allocated in the region of the splitter plates (8 gaps with 4 fibres per gap, Fig. 2). The arc is initiated by the separation of the movable contact from the fixed contact. After arc ignition, the arc emits radiation with is transmitted to photodiode sensors in the AIS through optical fibres. While the arc propagates through the chamber the AIS allows to detect the arc intensity related to the arc temperature. Table I shows the specification of the AIS used in this study [7].

A capacitor bank provided a half cycle wave of a short circuit current with the peak value of $1750 \mathrm{~A}$. Three tests were conducted under each identical vent condition. After three consecutive switchings, the splitter plates, arc runner, fixed and movable contacts were replaced for the next repeat tests.

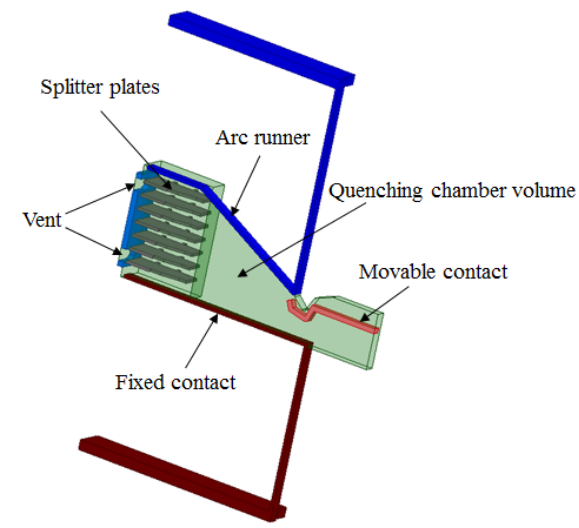

Figure 1. Half symmetric geometry of a quenching chamber in a FTA.

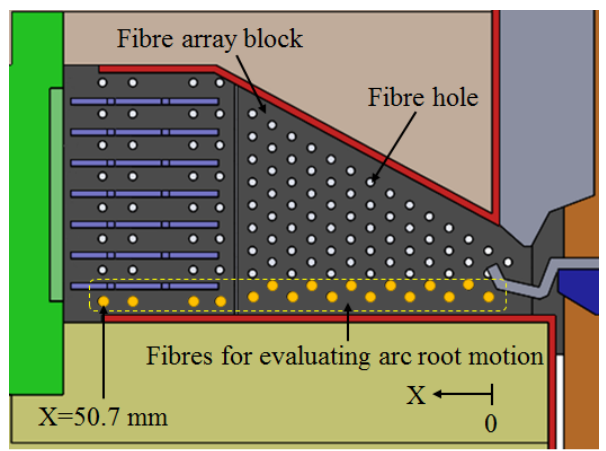

Figure 2. Fibre locations in a quenching chamber (horizontal section view).
TABLE I. SPECIFICATION OF AIS USED IN THIS WORK

\begin{tabular}{|c|c|}
\hline Item & Value \\
\hline Sampling rate & $1 \mathrm{MHz}$ \\
\hline Number of optical fibres & 109 \\
\hline Light intensity resolution & 8 bit $(0-255)$ \\
\hline Fibre length & $2 \mathrm{~m}$ \\
\hline Spectral sensitivity of photodiode & $320 \mathrm{~nm}-1060 \mathrm{~nm}$ \\
\hline
\end{tabular}

\section{B. Evaluating Arc Root Motion}

Arc root motion is evaluated by the centre of intensity method,

$$
x=\frac{\sum I_{i} X_{i}}{\sum I_{i}},
$$

where $x$ is the centre of light intensity, $I_{i}$ is the light intensity at a time for the fibre at position $X_{i}$ next to cathode surface [5], [6]. The data from 17 fibres near the fixed contact (the cathode electrode) shown in Fig. 2 are used for calculating the cathode arc trajectory in the $\mathrm{X}$ direction (from the ignition point to the region of the splitter plates).

\section{Vent Conditions}

Table II shows the vent conditions employed in the experiments. Three kinds of vents (closed, partially open and fully open) were used to investigate the effect of the vent size, whereas two kinds of vents ( 2 apertures and 12 apertures) were used for the study of the effect of the vent distribution. The identical size of vent area $(23 \%$ opening of the overall area) was adopted in the experiments of the vent distribution; however, there were different distributions as shown in Fig. 3.

TABLE II. VENT CONDITIONS

\begin{tabular}{|c|c|c|c|}
\hline Purpose of experiments & \multicolumn{3}{|c|}{ Vent conditions } \\
\hline $\begin{array}{c}\text { Effect of vent size } \\
\text { on arc motion }\end{array}$ & $\begin{array}{c}\text { Closed } \\
(0 \% \text { open })\end{array}$ & $\begin{array}{c}{ }^{1} \text { Partially open } \\
(23 \% \text { open })\end{array}$ & $\begin{array}{c}\text { Fully open } \\
(100 \% \text { open })\end{array}$ \\
\hline $\begin{array}{c}\text { Effect of vent distribution } \\
\text { on arc motion }\end{array}$ & $\begin{array}{c}2 \text { apertures } \\
(23 \% \text { open })\end{array}$ & $\begin{array}{c}12 \text { apertures } \\
(23 \% \text { open })\end{array}$ \\
\hline
\end{tabular}

${ }^{1}$ The partially open vent is the same one with the 2 apertures vent used in the study of the effect of the vent distribution, Fig. 3(a).

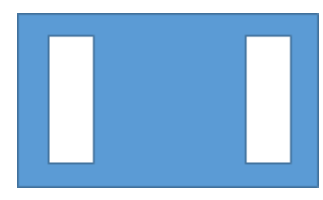

(a) 2 apertures vent

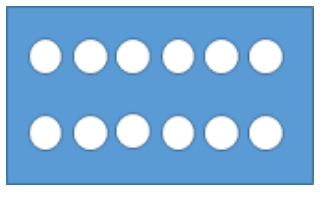

(b) 12 apertures vent
Figure 3. Two types of vent distribution. 


\section{RESUlTS AND DiSCUSSION}

\section{A. Analysis of Arc Motion and Arc Voltage Waveform}

Fig. 4 presents the arc voltage and the cathode arc root trajectory obtained by (1) during the switching process under the partially open vent condition. It is observed that there is synchronisation between the arc voltage drop and arc backmotion; i.e. the arc voltage falls significantly when the arc root moves backwards (towards the ignition region). Fig. 5 shows the measured arc images with corresponding the waveforms in Fig. 4. After ignition, the arc elongates as the movable contact parts from the fixed contact and the anode arc root jumps from the movable contact to the arc runner at around $4.0 \mathrm{~ms}$, Fig. 5(b). The arc gradually moves towards the splitter plates and the arc voltage rises; however, the cathode arc root suddenly moves backwards by $8 \mathrm{~mm}$ at $4.6 \mathrm{~ms}$ (see Fig. 5(d)) and there is another significant back-motion by $20 \mathrm{~mm}$ at $4.85 \mathrm{~ms}$ (see Fig. 5(h)), leading to notable drops of the arc voltage in Fig. 4. After then, the arc is forced again to enter the splitter plates by the gas flow and Lorentz forces, but it is seen that the arc is not able to stay stably at the splitter plates because of arc back-motion (see Fig. 5 (j), (1), (n) and (p)). Even though the arc fully enters the splitter plates, the reverse arc motion occurs afterwards, compare Fig. 5(m) with Fig. 5(n) and Fig. 5(o) with Fig. 5(p).

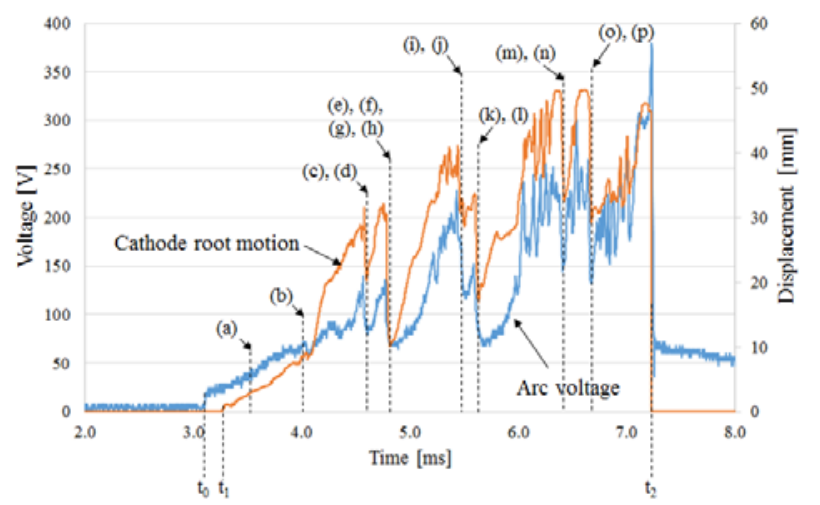

Figure 4. Arc voltage and cathode root trajectory waveforms: $t_{0}$ is the arc ignition time (or the contact separation time), $t_{1}$ is the starting time of the cathode root motion and $t_{2}$ is the time when the arc extinguishes.

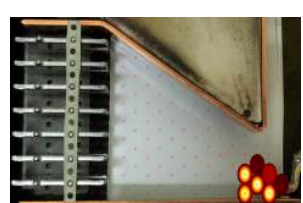

(a) $3.500 \mathrm{~ms}$

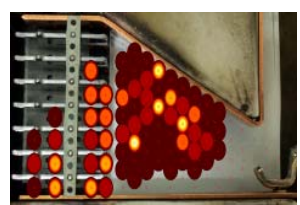

(c) $4.578 \mathrm{~ms}$

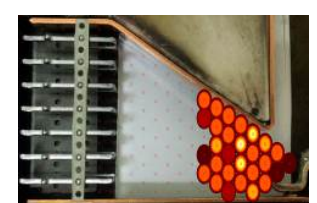

(b) $4.000 \mathrm{~ms}$

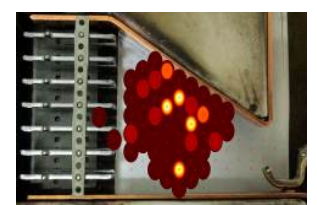

(d) $4.600 \mathrm{~ms}$

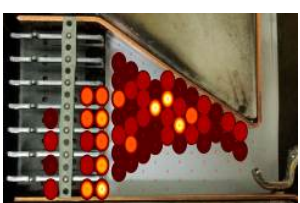

(e) $4.782 \mathrm{~ms}$

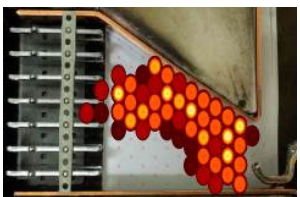

(g) $4.806 \mathrm{~ms}$

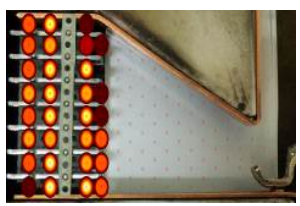

(i) $5.433 \mathrm{~ms}$

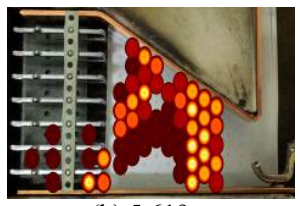

(k) $5.619 \mathrm{~ms}$

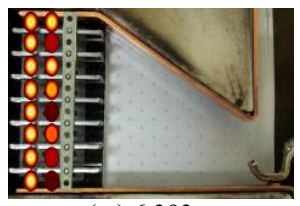

(m) $6.393 \mathrm{~ms}$

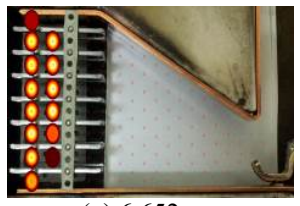

(o) $6.652 \mathrm{~m}$

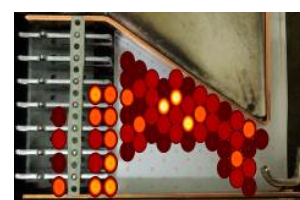

(f) $4.785 \mathrm{~ms}$

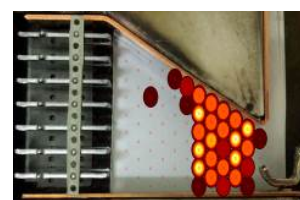

(h) $4.850 \mathrm{~ms}$

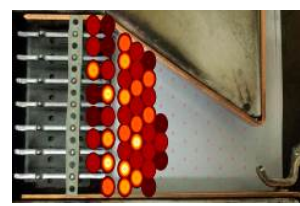

(j) $5.500 \mathrm{~ms}$

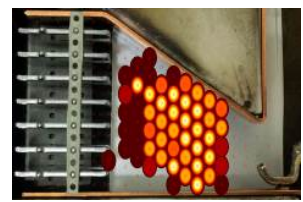

(1) $5.632 \mathrm{~ms}$

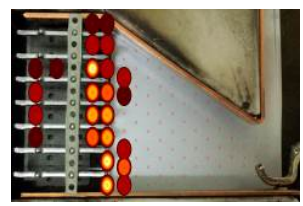

(n) $6.418 \mathrm{~ms}$

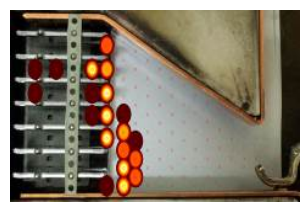

(p) $6.670 \mathrm{~ms}$
Figure 5. Arc images during interruption process: each image corresponds to time instances (a) to (p) in Fig. 4.

To evaluate the effect of the vent condition on arc motion and switching performance, several parameters are introduced based on the cathode root motion and arc voltage as shown in Fig. 4,

$$
\begin{gathered}
\bar{X}=\frac{\int_{t_{1}}^{t_{2}} x d t}{t_{2}-t_{1}}, \\
\bar{U}=\frac{\int_{t_{0}}^{t_{2}} U d t}{t_{2}-t_{0}}, \\
t_{\text {arcing }}=t_{2}-t_{0},
\end{gathered}
$$


where $\bar{X}$ is the average displacement of the cathode root, $\bar{U}$ is the average arc voltage, $t_{\text {arcing }}$ is the arcing time, $x$ is the cathode arc root trajectory (or the centre of light intensity), $U$ is the arc voltage, $t_{0}$ is the arc ignition time (or the contact separation time), $t_{1}$ is the starting time of the cathode root motion and $t_{2}$ is the time when the arc extinguishes.

\section{B. Effect of Vent Size on Arc Motion}

Table III shows the experimental results of the effect of the vent size on arc motion and switching performance. Each parameter value represents an average value from 3 repeated switching tests. In general, the arc moves further and more quickly towards the splitter plates (in the X direction in Fig. 2) and switching performance is improved as the vent size increases. Fig. 6 and 7 present the comparison of the cathode

TABLE III. RESUlTS OF EFFECT OF VENT SIZE

\begin{tabular}{|c|c|c|c|}
\hline & $\begin{array}{c}\text { Closed } \\
\text { (0\% open) }\end{array}$ & $\begin{array}{c}\text { Partially open } \\
\text { (2 apertures, } \\
\text { 23\% open) }\end{array}$ & $\begin{array}{c}\text { Fully open } \\
(\mathbf{1 0 0 \%} \text { open })\end{array}$ \\
\hline $\begin{array}{c}\bar{X} \\
{[\mathbf{m m}]}\end{array}$ & 23.2 & 25.6 & 34.5 \\
\hline $\begin{array}{c}\bar{U} \\
{[\mathbf{V}]}\end{array}$ & 95.3 & 124.6 & 143.3 \\
\hline \begin{tabular}{c}
$\boldsymbol{t}_{\text {arcing }}[\mathbf{m s}]$ \\
\hline
\end{tabular} & 5.08 & 4.01 & 3.66 \\
\hline
\end{tabular}

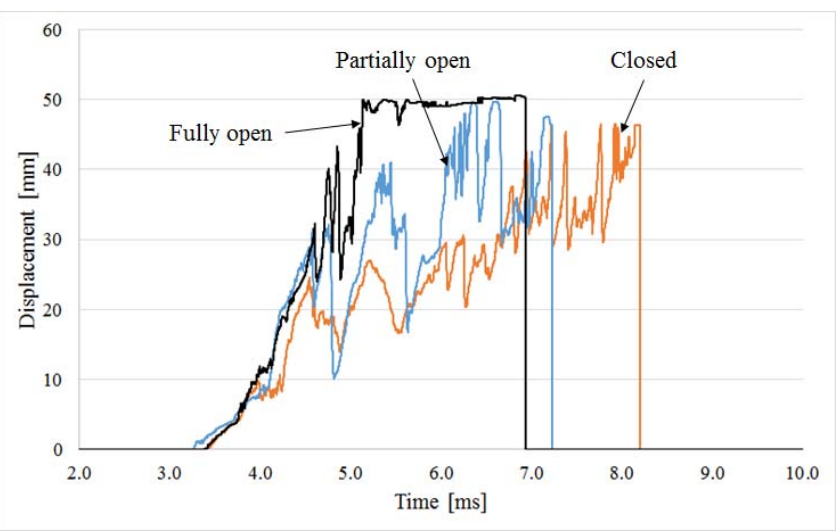

Figure 6. Cathode root trajectories depending on vent size.

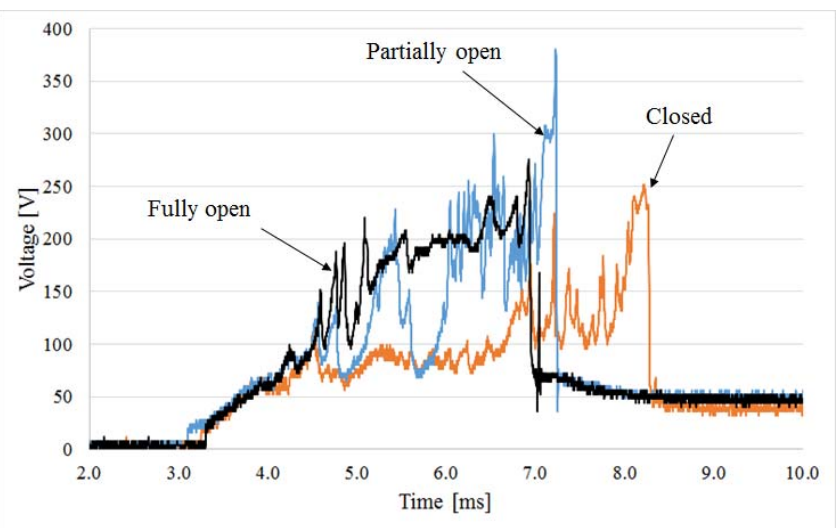

Figure 7. Arc voltage waveforms depending on vent size. root trajectories and arc voltage waveforms associated with the vent size. The arc in the fully opened test reaches the splitter plates in the shortest time and there is a relatively high and stable arc voltage when compared to the partially open and closed cases. As expected, the stable arc position corresponds to the stable voltage. It is seen that there are significant fluctuations in the cathode root trajectory of the partially opened test, causing notable drops of the arc voltage. Also, the lowest velocity of the cathode arc root is observed in the closed case, which leads to the low arc voltage during the whole switching process. Again, it is expected since the arc motion is blocked by high pressure built-up in front of the arc.

\section{Effect of Vent Distribution on Arc Motion}

Table IV shows the effect of vent distribution on the LVSD switching process. It can be said that the well distributed vent achieves better switching performance due to

TABLE IV. RESULTS OF EFFECT OF VENT DistRIBUTION

\begin{tabular}{|c|c|c|}
\hline & $\begin{array}{c}\text { 2 apertures } \\
\text { (23\% open) }\end{array}$ & $\begin{array}{c}\text { 12 apertures } \\
\text { (23\% open) }\end{array}$ \\
\hline $\begin{array}{c}\bar{X} \\
{[\mathbf{m m}]}\end{array}$ & 25.6 & 28.9 \\
\hline $\begin{array}{c}\bar{U} \\
{[\mathrm{~V}]}\end{array}$ & 124.6 & 134.9 \\
\hline $\begin{array}{c}\boldsymbol{t}_{\text {arcing }} \\
{[\mathrm{ms}]}\end{array}$ & 4.01 & 3.74 \\
\hline
\end{tabular}

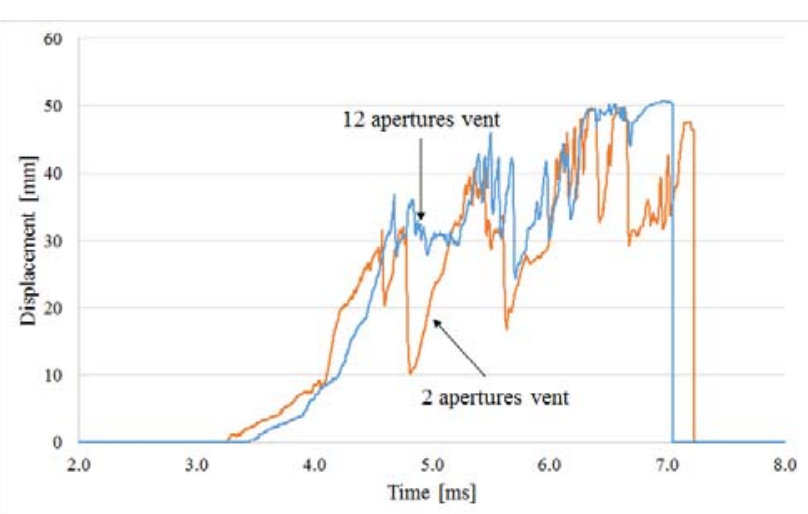

Figure 8. Cathode root trajectories depending on vent distribution.

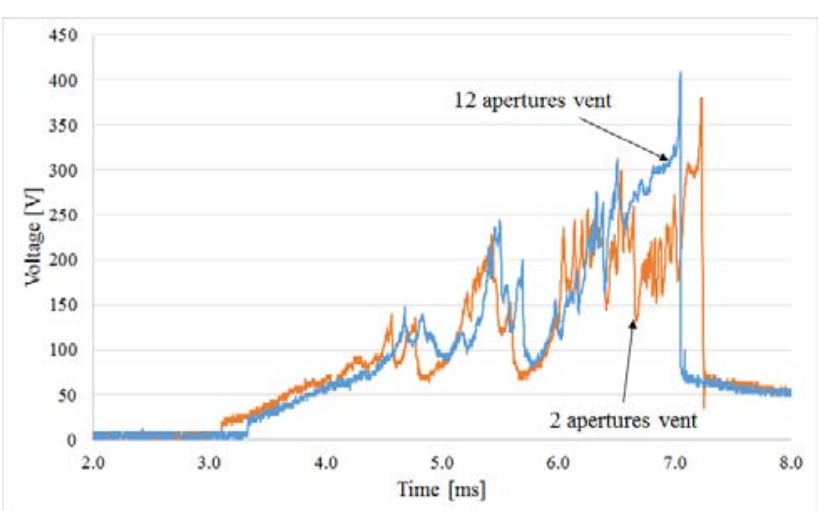

Figure 9. Arc voltage waveforms depending on vent distribution. 
decreased arc back-motion. Much less fluctuation is observed in the cathode root trajectory of the 12 apertures vent test when compared to the 2 apertures case as shown in Fig. 8. In addition, it is seen from Fig. 9 that the arc voltage in the 12 apertures test is higher than that in the 2 apertures case at the end of the process, resulting in the better current limitation.

\section{CONCLUSION}

In this paper, the investigation of the effects of vent condition on arc motion in the LVSD has been carried out in an attempt to understand a correlation between switching performance and gas-plasma motion. The cathode root trajectories have been obtained from AIS data and they used to analyse the effects of vent size and distribution on the switching process. It is shown that the arc moves further and more quickly if there is the larger vent opening area in the quenching chamber. In addition, the well distributed vents help to increase the arc motion velocity and to improve switching performance.

\section{REFERENCES}

[1] E. Belbel and M. Lauraire, "Behavior of switching arc in low-voltage limiter circuit breakers," IEEE Trans. Components, Hybrids, Manuf. Technol., vol. 8, no. 1, pp. 3-12, 1985.

[2] J. W. McBride, K. Pechrach, and P. M. Weaver, "Arc root commutation from moving contacts in low voltage devices," IEEE Trans. Components Packag. Technol., vol. 24, no. 3, pp. 331-336, 2001.

[3] L. Xingwen, C. Degui, W. Qian, and L. Zhipeng, "Simulation of the Effects of Several Factors on Arc Plasma Behavior in Low Voltage Circuit Breaker," Plasma Sci. Tech., vol. 7, no. 9, pp. 3069-3072, 2005.

[4] Q. Wang, X. Li, D. Chen, S. Member, M. Rong, and A. Abstract, "Simulation of the Venting Configuration Effects on Arc Plasma Motion in Low-Voltage Circuit Breaker," IEEE Trans. Plasma Sci., vol. 38 , no. 9 , pp. $2300-2305,2010$.

[5] P. A. Jeffery, "The motion of short circuit arcs in low-voltage current limiting miniature circuit breakers," Ph.D. dissertation, University of Southampton, United Kingdom, 1999.

[6] P. M. Weaver and J. W. McBride, "Magnetic and gas dynamic effects on arc motion in miniature circuit breakers," IEEE Trans. components, Packag. Manuf. Technol. Part A, vol. 17, no. I, pp. 39-46, 1994.

[7] Taiccaan website accessed at : http://www.taicaan.com 